\title{
Design and Experiment of Onboard Field 3D Topography Surveying System
}

\author{
Mingming Guo, Gang Liu, and Xinlei Li \\ Key Laboratory of Modern Precision Agriculture System Integration Research, Ministry of \\ Education, China Agricultural University \\ guomingming666666@163.com
}

\begin{abstract}
Laser-controlled land leveling system can obviously improve the planeness of the field and enhance the efficiency of irrigation. The 3D topographic information was needed for project design and evaluation of laser land leveling. In order to obtain the topographic information efficiently, an onboard field 3D topography surveying system was developed. The surveying system consisted of a measuring laser receiver, a GPS receiver, a controller and a hydraulic system. Besides topographic measurement, the system could also achieve laser land leveling. The measuring laser receiver was used to obtain the elevation and the GPS receiver was employed to obtain the longitude and latitude data. The data was fused in the controller to get the 3D topographic information. Field experiments were carried out in different speed and compared with the data from the fixed-point surveying method. The result showed the surveying system had a good consistency with the fixed-point surveying method in slower speed.
\end{abstract}

Keywords: Laser-controlled Land Leveling, Topographic Surveying, GPS.

\section{Introduction}

The application of laser-controlled land leveling technology can achieve high-precision agricultural land leveling and improve the field micro-topographic condition obviously. Therefore, the irrigation efficiency and irrigation uniformity can be increased, resulting in water saving and yield increasing[1]. Before and after Laser-controlled land leveling operations, the 3D topographic information was needed in order to develop a reasonable engineering design and evaluation of land leveling[2]. There were many surveying devices for measuring in engineering such as GPS, theodolite, total station, portable computer, etc. [3]. The accuracy and efficiency of measurement can be significantly improved by GPS and laser technology. In cooperation with the Ministry of Land and Recourses, a set of relatively efficiency and low cost portable field measurement system based on GPS and laser was developed by Research Center for Precision Agriculture of China Agricultural University in 2006.The height measurement error was less greater than $4 \mathrm{~cm}$, making up the great error of the GPS system in height measurement $[3,4]$. But the portable measurement system can only be applied for high precision topographic survey in a small area. A lot of time and manpower will be taken as to a large field and the efficiency will be decreased. Therefore, this study developed 
a new type of onboard field 3D topography surveying system, providing a kind of effective solution to obtaining the 3D topographic information automatically and saving manpower in large field. At the same time, the system was integrated with function of laser-controlled land leveling, improving the quality and efficiency of ground operations [5].

\section{System Analysis and Design}

A modular and integrated design concept was adopted. The system was divided into four separate parts: laser measurement system, GPS receiver, controller and hydraulic system. The structure was shown in Figure 1. Laser measuring receiver will receive the laser signal and send to the controller after treatment. Controller, as the controlling terminal and information processing platform, was responsible for gathering the information of GPS horizontal coordinates and elevation information of laser measuring receiver, display and storage, controlling the hydraulic system according to the position signal of receiver. Hydraulic control system will control the raise and lower of leveling bucket according to the output signal of the controller, realizing land leveling operation.

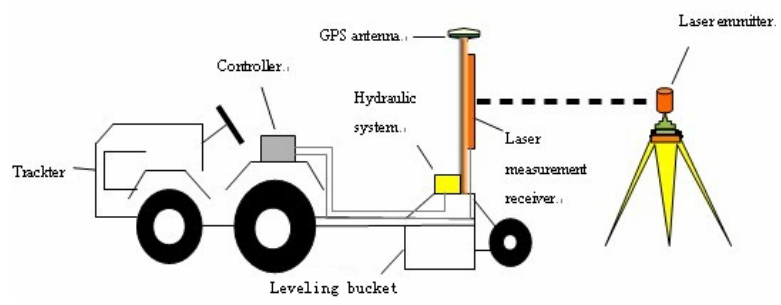

Fig. 1. Structure of onboard field 3D topography surveying system

\section{System Implementation}

\subsection{Design of Measuring Receiver}

Laser measuring receiver was an important part of onboard field 3D topography surveying system. Laser transmitter fired laser beam to form a base level above the working plane. Signal was produced and sent to the controller after the laser measuring receiver received real-time weak low-frequency laser beam.

The working principle of the laser measuring receiver was shown in Figure 2. Combanation filter was composed of red organic glass and interference filter. Red organic glass was used as the in-light window, which could greatly reduce the background light into the laser measuring receiver. Interference filter was used at the laser measuring receiver to further reduce the background light. Photo-electric cells were used to transform light signal into electrical signal. The low-noise preamplifier and main amplifier based on integrated amplifier were used to amplify the weak electrical signal effectively. The wave shaping circuit was employed to achieve better signal 
conditioning from spike pulse signal to digital TTL signal. The widening circuit was used to stretch the pulse width in order to be processed by the follow-up circuit more easily by the controller [6].

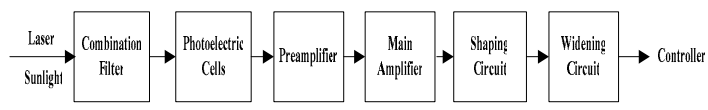

Fig. 2. Principle of measuring laser receiver

In order to achieve the requirement of effective laser signal receiving angle to $360^{\circ}$, the research formed rational design of spatial distribution of the cells, which was shown in Figure 3. 128 pieces of dimension $20 \mathrm{~mm} \times 5 \mathrm{~mm}$ photo-electric cells were divided into 32 layers and 4 rows. In each receiving layer, adjacent photo-electric cells were fixed vertically at the same height on two metal holders merged in square shape and can meet the requirement of effective laser signal receiving angle to $360^{\circ}$ [7].

Each column of adjacent photo-electric cells were installed at an interval of $2 \mathrm{~mm}$ in order to get the vertical measurement range to $70.2 \mathrm{~cm}$, while 32 pieces of photo-electric cells composed 32 groups of signals, corresponding height degree scale to 63 , meeting the requirement of precision measurement on elevation information.

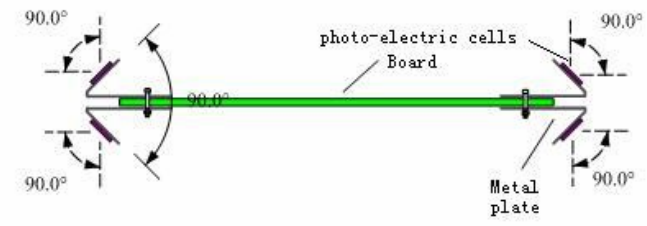

Fig. 3. Distribution of photo-electric cells in horizontal direction

\subsection{The Option of GPS Receiver}

Considering the effect of the speed to the accuracy of GPS, the research set GPS port on standard of RS232 form. Different GPS measurement equipment, such as GPS OEM board, high precision RTK DGPS receivers can be chosen to meet different requirement of measurement accuracy.

\subsection{Controller}

Controller was the monitoring and operating center of onboard field 3D topography surveying system. The paper designed a controller with two modes of measurement and land leveling. The functions of the modes were shown as follows:

(1) Measurement mode: receive and parse the GPS data, receive signal from the laser measuring receiver and calculate the relative elevation, display 3D information, data storage, indicate relative position of the receiver with LED indicator and LCD screen; 
(2) Land leveling mode: control hydraulic system to achieve the raise and lower of the leveling bucket according to the signal of the laser receiver, instruct the relative position of the receiver, achieve modes witching from manual to automatic.

\subsubsection{Design of the Controller's Hardware}

The research adopted ARM7 as CPU for the controller and the hardware circuit was shown in Figure 4. In measurement mode, the controller fused the data gathered from laser measuring receiver and GPS OEM board so as to get the 3D information of the topographic measurement point, stored date using $\mathrm{U}$ disk storage module, indicated the state of the system through LCD screen. In land leveling mode, the controller switched the signal from laser measuring receiver into control signal to hydraulic system and dominated the raise and lower of the leveling bucket, realizing land leveling.

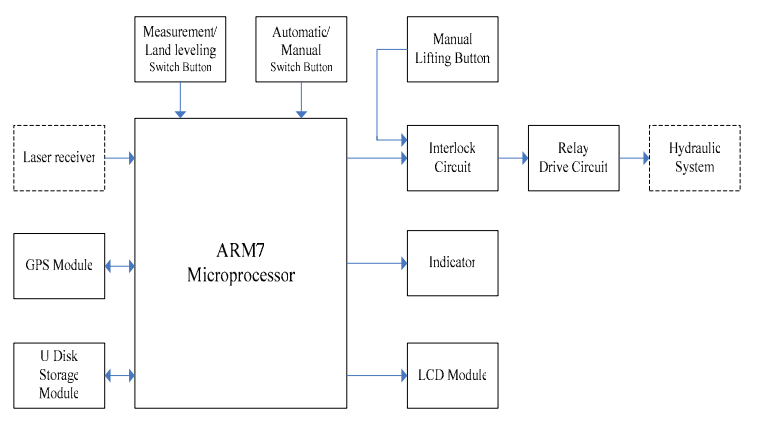

Fig. 4. Hardware circuit diagram of controller

\subsubsection{Design of the Controller's Software}

The controller's software needed to handle 5 projects: GPS data reception and processing, real-time elevation information processing, real-time LED indicating and LCD display, data storage and hydraulic system control. The diagram of the system task was shown in Figure 5.

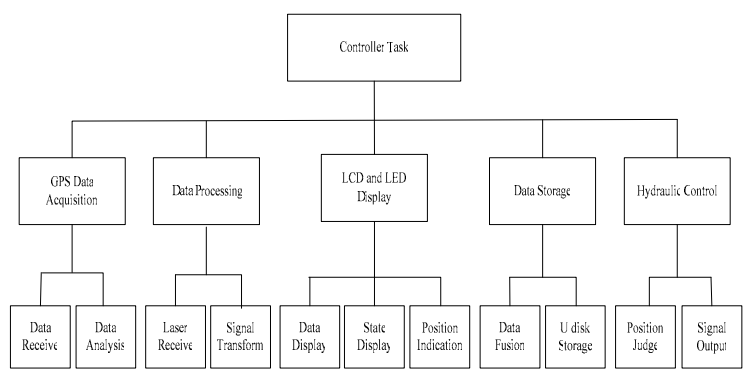

Fig. 5. Diagram of system task 


\subsection{Design of Hydraulic System}

Hydraulic system was mainly used to control the movements of the leveling bucket in order to achieve land leveling. The hydraulic control system accepted signals from the intelligent controller and would supply oil to raise or lower the leveling bucket automatically to maintain the laser receiver on right position [8]. The hydraulic system required quick response speed and high control precision, so it was a major problem to matching the system to the controller. The desired rate at which the bucket raise and lower would depend on the operating speed. The faster the ground speed the faster the bucket would need to adjust. A remote relief valve was used before the control valve; the pressure setting on this valve would change the raise/ lower speed. The principle of hydraulic pressure controller was shown in Fig.6.

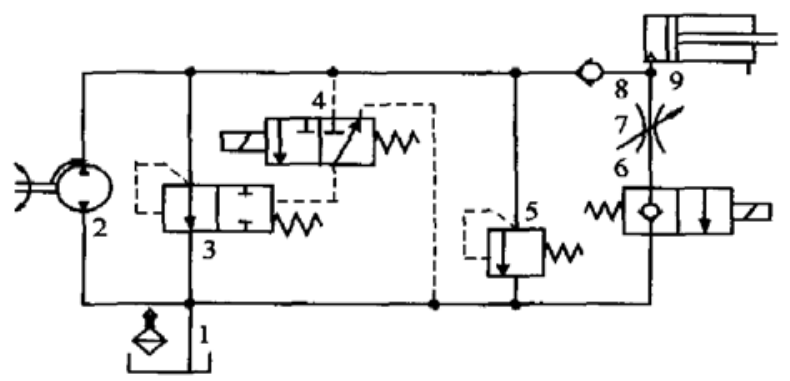

1-oil box, 2-oil pump, 3-hydraulically operated direction control valve, 4- solenoid directional control valve, 5-overflow valve, 6-solenoid lower-control valve, 7-speed adjusting valve, 8 -single direction valve 9- hydraulic ram

Fig. 6. Principle of hydraulic pressure controller

\section{Field Experiment}

\subsection{Experiment Materials and Methods}

In April 2010, at Experimental Station of China Agricultural University, a field at the length of $70 \mathrm{~m}$ and width of $60 \mathrm{~m}$ was chosen and East Red 754 tractor was selected as traction power.3D topographic survey experiments were taken respectively in speed of $20 \mathrm{~km} / \mathrm{h}$ and $10 \mathrm{~km} / \mathrm{h}$. The experiment selected AgGPS132 as the GPS receiver and applied portable 3D topographic survey system developed by the Precision Agriculture Center of China Agricultural University as a comparison. The test placed the antenna of GPS and radio station on the leveling bucket with magnetic sucker in order to receive differential position information. The laser measuring receiver was installed at a suitable location on the mast of leveling bucket for the purpose of receiving laser signals. 


\subsection{Experiment Results}

The relative elevation of ground statistics eigenvalues measured by the portable survey system from fixed-point and two-vehicle speed were shown in Table 1. Compared with fixed-point measurements, the maximum relative elevation difference obtained from fast speed $(20 \mathrm{~km} / \mathrm{h})$ and slow speed $(10 \mathrm{~km} / \mathrm{h})$ reached to $3.7 \mathrm{~cm}$ and $1.5 \mathrm{~cm}$ respectively. The minimum difference reached to $1.6 \mathrm{~cm}$ and $0.5 \mathrm{~cm}$ respectively. The average deviation attained to $0.6 \mathrm{~cm}$ and $0.5 \mathrm{~cm}$, while the standard deviation got a small deviation. As the difference between the number and the location of measurement points, it was difficult to analyze statistical data rigorously at the same point and the onboard state measurements. But to the whole landscape, the small difference of standard deviation can be reflected from the 3D topographic map in Figure 7. The difference on elevation at the edge of the field was mainly caused by large bumps when the tractor steering to the place, resulting in laser signal exceeded the range of laser measuring receiver and lost the measuring points.

Table 1. Experiment results

\begin{tabular}{ccccc}
\hline $\begin{array}{c}\text { Statistics } \\
\text { eigenvalue }\end{array}$ & $\operatorname{Max}(\mathrm{cm})$ & $\operatorname{Min}(\mathrm{cm})$ & Mean(cm) & $\begin{array}{c}\text { Standard } \\
\text { error }(\mathrm{cm})\end{array}$ \\
\hline $\begin{array}{c}\text { Fixed-point } \\
\text { measurement } \\
\text { Slow-speed } \\
\text { onboard }\end{array}$ & 137.0 & 105.0 & 116.7 & 4.67 \\
measurement & 138.5 & 105.5 & 117.2 & 4.57 \\
$\begin{array}{c}\text { Fast-speed } \\
\text { onboard }\end{array}$ & 140.7 & 106.6 & 117.3 & 4.51 \\
measurement & & & & \\
\hline
\end{tabular}

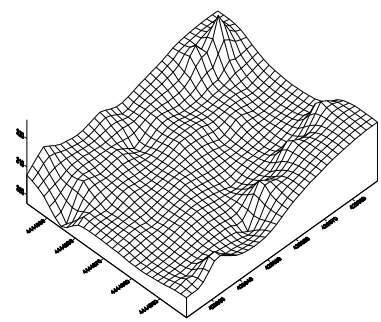

( a )

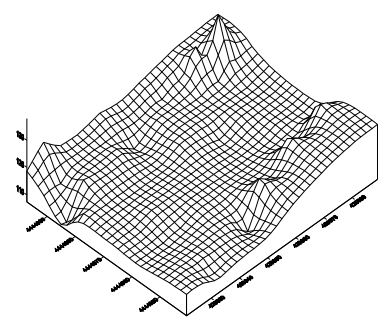

( b )

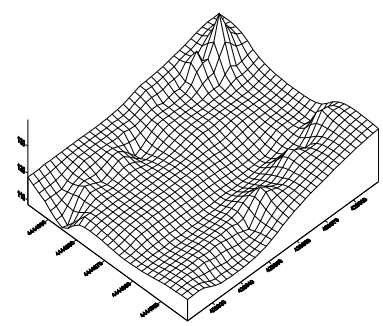

( c)

(a) Fixed-point measurement (b) Slow-speed onboard measurement (c) Fast-speed onboard measurement

Fig. 7. Comparison of $3 \mathrm{D}$ topographic map for field survey by fixed-point and in different moving speeds 
The relative elevation of ground Statistics eigenvalues from Table 1 showed that the maximum relative elevation difference was $2.2 \mathrm{~cm}$ and the minimum relative elevation difference was $1.1 \mathrm{~cm}$, while the average value and standard error were approximate, which meant the measurement in different speed had a big influence on extremum and little effect on characteristics of the overall landscape. Even so, the influence of speed to the measurement result can be seen from Figure 8. It was a Statistical chart of percentages of the absolute difference $>2 \mathrm{~cm}$ between elevations and their average values. It was clear that the percentage accounted in fast speed was bigger than in the slow speed. This showed that the measurement result got from fast speed had much more discrete data and the accuracy in slow speed was greater than fast speed.

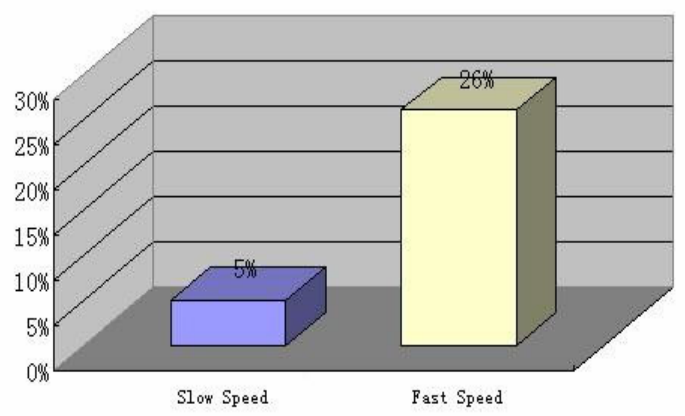

Fig. 8. Statistical chart of percentages of the absolute difference $>2 \mathrm{~cm}$ between elevations and their average values under two moving speeds

\section{Conclusion}

This paper presented a new type of onboard field 3D topography surveying system. The experiment result indicated that the influence of the tractor's speed to the measurement accuracy was obvious and the measurement accuracy in slow speed was greater than in the fast speed. Different speed should be adopted according to the field condition when doing measurement with onboard field 3D topography surveying system. Slow and uniform speed was important to guarantee the measurement accuracy.

\section{Acknowledgement}

This research is sponsored by the project 2008BAB38B06 and 2009BAC55B01. All of the mentioned support is gratefully acknowledged.

\section{References}

1. Rickman, J.F.: Manual for laser land leveling, pp. 1-5. Indian Council of Agricultural Research, New Delhi (2002)

2. Li, Y., Xu, D., Li, F.: Application of GPS Technology in Agricultural Land Leveling Survey. Transaction of the CSAE 21(1), 66-70 (2005) 
3. Chen, Y.: Research and Development on Field Topography Measurement Equipment based on GPS and Laser Techniques. China Agriculture University, Beijing (2006)

4. Zhang, M., Chen, Y., Jia, W.: Design of 3D Topographic Information Measuring System. Journal of Jilin University: Engineering and Technology Edition 37(6), 1451-1454 (2007)

5. Yang, Z.: Research and Development on Field Topography Survey System based on GPS and Laser Techniques. China Agriculture University, Beijing (2008)

6. Lv, Q.: Improvement and Experimentation of Laser Controlled Land Leveling System. China Agriculture University, Beijing (2007)

7. Lin, J.: Research and Development on Receiver and Controller for Laser Controlled Land Leveling System. China Agriculture University, Beijing (2004)

8. Si, Y., Liu, G., Yang, Z.: Development and Experiment on laser land Leveling System. Journal of Jiangsu University: Natural Science Edition 30(4), 69-74 (2009) 